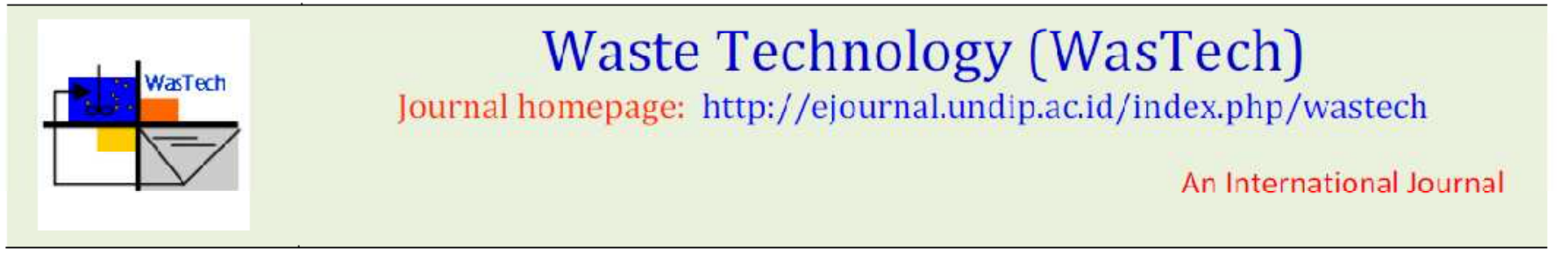

\title{
Liquid and Gaseous Fuels from Waste Plastics by Sequential Pyrolysis and Catalytic Reforming Processes over Indonesian Natural Zeolite Catalysts
}

\author{
Mochamad Syamsiro ${ }^{1 *}$, Shuo Cheng ${ }^{4}, \mathrm{Wu} \mathrm{Hu}^{4}$, Harwin Saptoadi², Nosal Nugroho Pratama², Wega \\ Trisunaryanti ${ }^{3}$, Kunio Yoshikawa ${ }^{4}$
}

\footnotetext{
${ }^{1}$ Center for Waste Management and Bioenergy, Janabadra University, Jl. T.R. Mataram 55-57, Yogyakarta 55231, Indonesia

2 Department of Mechanical and Industrial Engineering, Gadjah Mada University, Jl. Grafika 2, Yogyakarta 55281, Indonesia

${ }^{3}$ Department of Chemistry, Gadjah Mada University, Sekip Utara, Yogyakarta 55281, Indonesia

${ }_{4}^{4}$ Department of Environmental Science and Technology, Tokyo Institute of Technology, G5-8, 4259 Nagatsuta, Midori-ku, Yokohama 226-8502, Japan

e-mail: syamsiro@janabadra.ac.id
}

\begin{abstract}
In this study, the performance of several differently treated natural zeolites in a sequential pyrolysis and catalytic reforming of plastic materials i.e. polypropylene (PP) and polystyrene (PS) were investigated. The experiments were carried out on two stage reactor using semi-batch system. The samples were degraded at $500^{\circ} \mathrm{C}$ in the pyrolysis reactor and then reformed at $450^{\circ} \mathrm{C}$ in the catalytic reformer. The results show that the mordenite-type natural zeolites could be used as efficient catalysts for the conversion of PP and PS into liquid and gaseous fuel. The treatment of natural zeolites in $\mathrm{HCl}$ solution showed an increase of the surface area and the Si/Al ratio while nickel impregnation increased the activity of catalyst. As a result, liquid product was reduced while gaseous product was increased. For PP, the fraction of gasoline ( $\left.\mathrm{C}_{5}-\mathrm{C}_{12}\right)$ increased in the presence of catalysts. Natural zeolite catalysts could also be used to decrease the heavy oil fraction $\left(>C_{20}\right)$. The gaseous products were found that propene was dominated in all conditions. For PS, propane and propene were the main components of gases in the presence of nickel impregnated natural zeolite catalyst. Propene was dominated in pyrolysis over natural zeolite catalyst. The high quality of gaseous product can be used as a fuel either for driving gas engines or for dual-fuel diesel engine.
\end{abstract}

Keywords - Pyrolysis, Catalytic reformer, Waste plastics, Fuels, Natural zeolites.

Submission: September 24, $2014 \quad$ Correction: October 5, $2014 \quad$ Accepted: October 12, 2014

Doi: http://dx.doi.org/10.12777/wastech.2.2.44-51

[How to cite this article: Syamsiro, M., Cheng, S., Hu, W., Saptoadi, H., Pratama, N.N., Trisunaryanti, W., Yoshikawa, K. (2014). Liquid and Gaseous Fuels from Waste Plastics by Sequential Pyrolysis and Catalytic Reforming Processes over Indonesian Natural Zeolite Catalysts. Waste Technology, 2(2), 44-51. doi: http://dx.doi.org/10.12777/wastech.2.2..44-51]

\section{Introduction}

Economic development in the era of globalization led to an increase in plastic consumption resulting in rapid increase of waste plastic generation in the world. There are several main approaches for recycling waste plastics, i.e. material recycling, feedstock or chemical recycling and energy recovery. Though various kinds of techniques have been proposed for the conversion of waste plastics, it is generally accepted that material recycling is not a longterm solution to the present problem. Thus, feedstock recycling and energy recovery are more attractive ones [1]. Waste plastics are one of the most promising resources for oil production because of its high calorific value and due to the increasing availability in local communities. Unlike paper and wood, plastics do not absorb much moisture and the water content of plastics is far lower than the water content of biomass [2].

Feedstock recycling is one of the valorization strategy to recycle waste plastics via pyrolysis which involves thermochemical decomposition of organic and synthetic materials at elevated temperatures in the absence of oxygen to produce fuels. The process is usually conducted at temperatures between $500-800^{\circ} \mathrm{C}$ [3]. These pyrolytic products can be divided into liquid fraction, gas fraction and solid residues [4]. The low thermal conductivity and high viscosity of plastics are the major problems for the cracking reactor design. Therefore, the reactor design becomes important parameter in feedstock recycling of plastics. Several reactor systems have been developed and used such as batch/semi batch [5], fixed bed, fluidized bed, 
spouted bed, microwave [6] and screw kiln. Batch or semibatch reactors have been used by many researchers because of its simple design and easy operation. However, the thermal degradation of plastics has some major drawbacks such as a very broad product range and requires high temperature. These facts strongly limit their applicability and especially increase the cost of feedstock recycling for waste plastic treatment [7].

Catalytic degradation therefore provides means to address these problems. The use of catalyst is expected to reduce the reaction temperature, to increase the decomposition speed, and to upgrade the products. A wide variety of catalysts have been tested by researchers such as zeolite, silica alumina, and FCC catalysts [8-11]. Each catalyst has different structure and composition which affects the fuel products. Direct catalytic cracking has been used widely due to several advantages, mostly in terms of the energy efficiency, with regards to the use of the reactor, the reaction temperature and the residence time.

Cracking reactions have also been studied for most polymers showing that the nature of the resulting products depends primarily on the polymer type. Catalytic pyrolysis of polypropylene (PP) has been studied by Ji et al. [12] using a fluidized bed reactor. The gasoline obtained in this study has Research Octane Number (RON) in the range of 84-88 while the cetane index for diesel fuel lies in the range of 40.5-45.3. Onwudili et al. [13] investigated the pyrolysis of polyethylene and polystyrene in a closed batch reactor to study the effect of the temperature and the residence time. The closed batch system can be effectively used to produce high grade fuel-like oils for energy production as well as chemicals.

However, direct catalytic cracking of waste plastics has a number of drawbacks which has prevented its commercial success. The difficulty to recover the catalyst after use, which increases the operational cost and rapid deactivation of catalyst due to the deposition of carbonaceous matter and the poisoning effect of extraneous elements and impurities such as chlorine, sulphur and nitrogen containing species that maybe present in the waste plastics are the main problems for this system [3]. Therefore, separation of the catalytic reforming reaction from the pyrolysis stage can be applied to overcome these problems. This method has been firstly tested by Bagri and Williams $[14,15]$ for polyethylene and polystyrene using zeolite-Y and ZSM-5 catalysts. Pyrolysis and the catalytic reforming of PS feedstock shows an increase in the gas yield and reduction in the oil yield. The use of other catalysts such as silica alumina and Al-MCM-41 have also been investigated by others $[10,16]$. Miguel et al. [16] have studied this system to valorize waste agricultural polyethylene film using HZSM-5 and Al-MCM-41 catalysts. Pyrolysis over AlMCM-41 catalyst produced heavier hydrocarbon products than HZSM-5 catalyst.

However, the use of catalyst is the main cost burden for recycling of plastic wastes by pyrolysis. Reducing the catalyst cost for small scale application in developing countries like Indonesia is very interesting challenges. Natural zeolites which can be found in many places worldwide including Indonesia might be used as a candidate for this purpose instead of the commercial catalysts. However, natural zeolites can not be used directly as a catalyst without pretreatment because the catalytic properties are not as good as commercial catalysts. Some preparation and modification can be done to natural zeolites such as calcination, acid and alkali treatment and metal impregnation [17] to improve the properties and to enhance the catalytic performance of the catalyst.

Jeong et al. [18] investigated the catalytic performance of alkali-treated natural zeolites from Korea in the liquidphase catalytic degradation of high density polyethylene (HDPE). Alkali treatment of natural zeolites with moderate $\mathrm{NaOH}$ solution brought about the formation of mesopores and decrease in acid site selectivity, resulting in a considerable improvement of its catalytic activity. The similar previous work has been done by Park et al. [19] with a different treatment. Natural zeolites were ionexchanged with $\mathrm{NH}_{4} \mathrm{Cl}$ solution to improve the catalytic performance. Another work has also been conducted by Fernandes et al. [20] using natural zeolite chabazite from Brazil with ammonium exchanged treatment. The performance of acid treated natural zeolites in catalytic degradation of polypropylene (PP) has been studied by Hwang et al. [21]. The treatment with boric and phosphoric acid showed an increase of surface area and pore volume compared to those of original natural zeolites and affected the liquid products which have a narrower range of carbon numbers compared with those obtained by the thermal degradation.

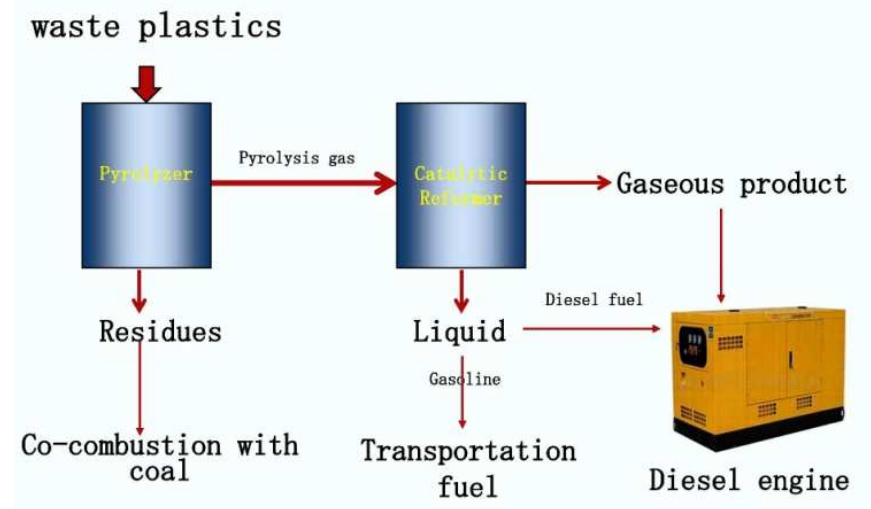

Figure 1. A schematic diagram of proposed system for converting waste plastics into fuels.

The use of natural zeolites for catalytic degradation of polystyrene (PS) has been investigated by Lee et al. [1]. The performance of natural zeolites after ion-exchanged with $\mathrm{NH}_{4} \mathrm{Cl}$ solution on the degradation of PS was as effective as HZSM-5 for the production of liquid oils with carbon numbers of $\mathrm{C}_{5}-\mathrm{C}_{12}$ without severe deactivation. Natural zeolite catalyst produced aromatic liquid oils with over $99 \%$ of selectivity. This catalyst also showed a decrease of 
styrene and an increased selectivity towards ethylbenzene and propylbenzene compared to that of thermal degradation. However, direct catalytic cracking method has been used by all researchers which has several drawbacks as mentioned above. Therefore, in this study, we propose a sequential pyrolysis and catalytic reforming system for plastics degradation using modified Indonesian natural zeolite. Our proposed system will utilize all kind of products as fuels including liquid, gaseous and solid products as shown in Figure 1. This novel proposed system will utilize liquid and gaseous products together for fueling a dual-fuel diesel engine to generate electricity. This power can be utilized for supplying the electricity to the plant itself and the excess power will be sent to outside of the plant. The solid products will be used for co-combustion with coal and biomass which can be utilized as a heating source for pyrolysis.

\section{Materials and Methods \\ 2.1 Materials}

The feedstocks used for these experiments were polypropylene (PP) and polystyrene (PS) granules manufactured by Tosoh Co. in Japan. The natural zeolite was collected from Klaten, Indonesia. $\mathrm{HCl}, \mathrm{Ni}\left(\mathrm{NO}_{3}\right)_{2} \cdot 6 \mathrm{H}_{2} \mathrm{O}$ and distilled water were obtained from Waco chemicals.

\subsection{Preparation of catalysts}

Three types of natural zeolites, different in pretreatment procedure, were used to test their catalytic performance in the degradation of polypropylene (PP) and polystyrene (PS). The raw natural zeolites were ground, sieved to 100 mesh particles size and washed with distilled water at the room temperature to remove the water soluble impurities. The washed natural zeolite was dried in an oven at $120^{\circ} \mathrm{C}$ for 5 hours and calcined at $500^{\circ} \mathrm{C}$ for 3 hours. This sample was named as A-NZ and used for the first catalyst. The A-NZ sample was used to prepare the acid treated catalyst. It was prepared by treating $20 \mathrm{~g}$ of A-NZ with 500 $\mathrm{ml}$ of $1 \mathrm{M} \mathrm{HCl}$ solution under the reflux condition at the atmospheric pressure for 1 hour. After the $\mathrm{HCl}$ treatment, the sample was filtered and washed with distilled water until no chloride ion was detected by using $\mathrm{AgNO}_{3}$ solution, after which the sample was dried at $120^{\circ} \mathrm{C}$ for 5 hours and calcined at $500^{\circ} \mathrm{C}$ for 3 hours. This sample was named as $\mathrm{H}$ $\mathrm{NZ}$ and used for the second catalyst.

The third catalyst was made by mixing $20 \mathrm{~g}$ of A-NZ sample with $1 \mathrm{~g}$ of $\mathrm{Ni}\left(\mathrm{NO}_{3}\right)_{2} \cdot 6 \mathrm{H}_{2} \mathrm{O}(1 \mathrm{wt} \%$ based on $\mathrm{Ni}$ metal) in distilled water at $75^{\circ} \mathrm{C}$ and magnetically stirred for 3 hours, after which the solvent was evaporated. After drying at $120^{\circ} \mathrm{C}$ for 5 hours, the nickel-containing sample was calcined at $500^{\circ} \mathrm{C}$ for 3 hours. This sample was named as Ni-NZ.

\subsection{Pyrolysis and catalytic reforming of plastics}

Pyrolysis and catalytic reforming experiments were carried out using semi-batch two-stage reactors. It consists of the pyrolysis reactor (pyrolyzer) and the catalytic reforming reactor (reformer). The schematic diagram of the experimental apparatus is shown in Figure 2. The pyrolyzer and the reformer were made of stainless steel and covered with electric heaters. The pyrolyzer`s inner diameter and the height were $30 \mathrm{~mm}$ and $200 \mathrm{~mm}$, respectively. The reformer's inner diameter and the height were $10 \mathrm{~mm}$ and $200 \mathrm{~mm}$, respectively. The reaction temperatures in both the pyrolyzer and the reformer were controlled with K-type thermocouples and heaters. A double-tube condenser was installed at the outlet of the reformer to separate gas and liquid products.

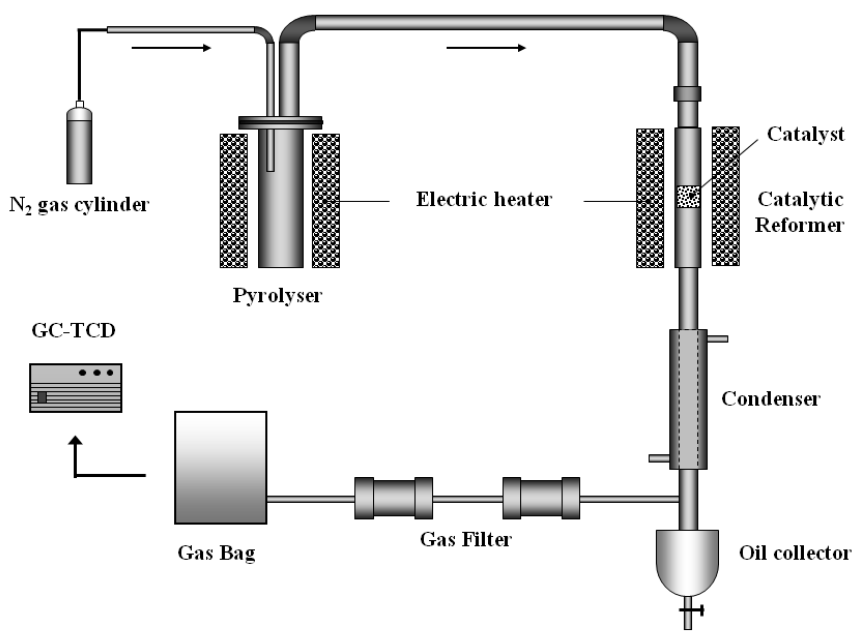

Figure 2. A schematic diagram of the experimental apparatus.

In these experiments, $50 \mathrm{~g}$ of the feedstock was fed into the pyrolizer, where the material was melted and then volatilized into the reformer. The catalyst $(1 \mathrm{~g})$ was loaded in the reformer, where the pyrolysis gas generated in the pyrolizer was reformed. Initially, the reformer was heated up to the preset temperature and then air in the reactors was replaced with $\mathrm{N}_{2}$ carrier gas followed by heating the pyrolyzer to the preset temperature. The nitrogen gas flow rate was $100 \mathrm{ml} \mathrm{min}^{-1}$. After the reforming reaction, the gas was cooled in the condenser to recover liquid products. Liquid products were then collected and weighed for the mass balance calculation. The remaining solids deposited in the pyrolyzer was defined as the residue, and the carbon left in the catalyst bed was defined as coke. Because the total amount of the residue and the coke was very small, we call the total as the solid product.

The experiments were carried out at the pyrolyzer temperature of $500^{\circ} \mathrm{C}$ and the reformer temperature of $450^{\circ} \mathrm{C}$. The gaseous products were collected in a gas bag for 2 hours. Experiments using similar conditions but in the absence of catalyst were also conducted for comparison.

\subsection{Characterization of catalysts and products}

The bulk structure of natural zeolite was confirmed by the X-Ray Diffraction (XRD) analysis (Rigaku Corp., Japan) using the Copper $\mathrm{K}$ alpha radiation. The composition of natural zeolite was determined by the X-ray Fluorescence 
(XRF) analyser. Nitrogen adsorption-desorption measurements were conducted at $77 \mathrm{~K}$ on a Belsorp-mini II (Bel Japan). The BET specific surface area $\left(S_{B E T}\right)$ was calculated from the adsorption data in the relative pressure. The Scanning Electron Microscope (SEM: JSM-5310LV Microanalyzer, JEOL Co.) was employed to determine the surface morphology of catalysts. The fraction of liquid products were analysed by using a gas chromatographymass spectrometry (GC-MS, QP2010S Shimadzu). The gaseous product composition was measured by a gas chromatograph equipped with a thermal conductivity detector (GC-TCD, Agilent Technologies Inc. USA).

\section{Results and discussion}

\subsection{Characterization of catalysts}

In order to examine the change of pore structure in the natural zeolite and its $\mathrm{HCl}$-treated sample, the XRD patterns of samples are shown in Figure 3. The crystalline structures of natural zeolites vary depending on their mining sites. It can be seen that the main structure of the natural zeolite catalyst was identified to be mordenite. Most of the peaks observed at $2 \mathrm{~T}$ (degree) $=5-35$ for the natural zeolite samples can be assigned to be those of mordenite type crystalline matter as reported by Trisunaryanti et al [22]. The samples showed relatively broad base lines. This suggests that the samples contain amorphous and crystalline impurities. After acid treatment, some impurity peaks of A-NZ disappeared which indicates that the treatment could remove a part of the impurities, while the crystalline structure was not decomposed.

The scanning electron microscope (SEM) images of natural zeolites before and after the acid treatment are shown in Figure 4. It can be observed that natural zeolite has a lamellar pattern and an irregular morphology. After the $\mathrm{HCl}$ treatment, it can be seen that the physical destruction was appeared which mean that the $\mathrm{HCl}$ treatment could remove some crystalline impurities as discussed previously. This is consistent with the XRD result shown in Figure 3.

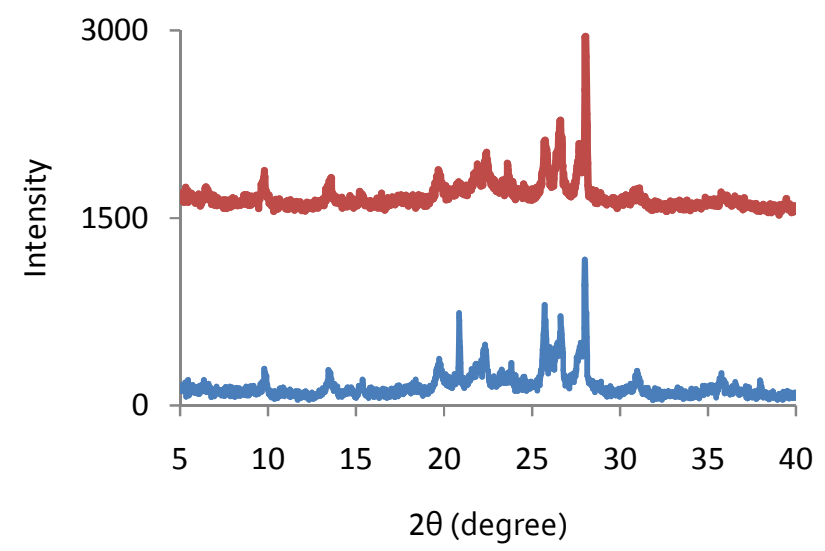

Figure 3. X-Ray powder diffraction pattern of natural zeolite samples before and after $\mathrm{HCl}$ treatment.

The chemical composition and the BET surface area of natural zeolites before and after the $\mathrm{HCl}$ treatment are listed in Table 1. It can be seen that the acid treatment of A$\mathrm{NZ}$ ( $\mathrm{Si} / \mathrm{Al}$ ratio=4.21) caused dealumination, which is indicated by the increase of the $\mathrm{Si} / \mathrm{Al}$ ratio. The relative ratios of alkaline and alkaline earth elements to Si were also found to have decreased by the treatment. Releasing aluminium and ferric ions indicated the partial destruction of the zeolite structure which is consistent with the SEM images.

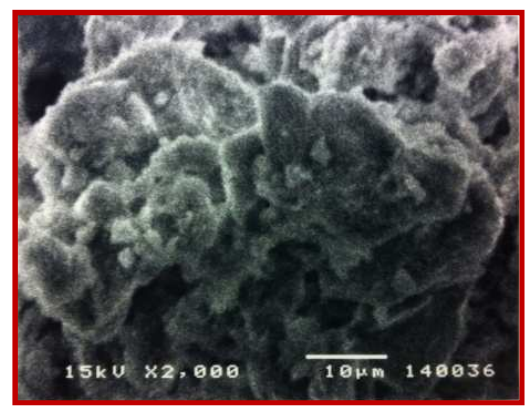

A-NZ

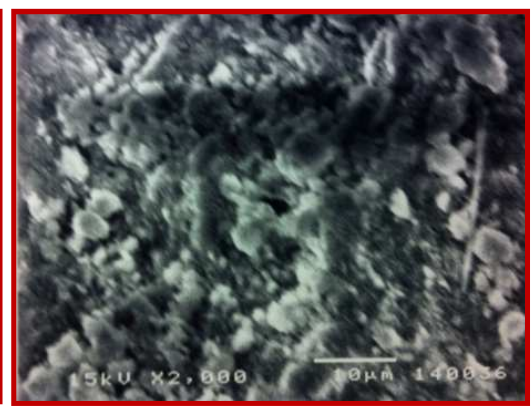

$\mathrm{H}-\mathrm{NZ}$

Figure 4. Scanning electron microscopy (SEM) images of natural zeolite samples.

Table 1. Chemical composition and BET surface area of natural zeolite before and after HCl treatment.

\begin{tabular}{lccccccc}
\hline & $\mathrm{Si} / \mathrm{Al}$ ratio & $\mathrm{Na} / \mathrm{Si}$ & $\mathrm{Mg} / \mathrm{Si}$ & $\mathrm{K} / \mathrm{Si}$ & $\mathrm{Ca} / \mathrm{Si}$ & $\mathrm{Fe} / \mathrm{Si}$ & $\mathrm{S}_{\text {BET }}\left(\mathrm{m}^{2} \cdot \mathrm{g}^{-1}\right)$ \\
\hline $\mathrm{A}-\mathrm{NZ}$ & 4.21 & 0.007 & 0.009 & 0.021 & 0.238 & 0.093 & 91.146 \\
$\mathrm{H}-\mathrm{NZ}$ & 6.75 & 0.002 & 0.008 & 0.010 & 0.050 & 0.036 & 233.94 \\
\hline
\end{tabular}


The increase of the $\mathrm{Si} / \mathrm{Al}$ ratio will increase the stability of the crystal framework and reduce the coke formation during the catalytic cracking. The acid treatment has also increased the surface area which can be seen from the increase of the BET surface area. It will increase the surface area contact between the catalyst and the pyrolysis gas so that longer chain hydrocarbons can be cracked into lighter hydrocarbons.

\subsection{Pyrolysis and catalytic reforming of polypropylene}

Polypropylene (PP) was degraded at $500^{\circ} \mathrm{C}$ in the pyrolyzer and then reformed at $450^{\circ} \mathrm{C}$ in the catalytic reformer. The experiments were done in the absence and presence of the catalyst. Three types of catalyst were used i.e. A-NZ, H-NZ and Ni-NZ. The liquid, gas, and solid product yields from a sequential pyrolysis and catalytic reforming of PP with and without the catalyst are shown in Figure 5. Pyrolysis at $500^{\circ} \mathrm{C}$ in the absence of the catalyst produced $91.6 \%$ of oil. Similar result has been found by Sarker et al. [23] which obtained $92 \%$ of oil. In the presence of the natural zeolite catalysts, the oil yields were reduced within the range of $83.8-86.4 \%$. The lower liquid yields have been obtained by Ji et al. [12] which produced about $50 \%$ of oils when utilizing a fluidized bed reactor. Theoretically, a fluidized bed system can enhance the heat transfer to the plastic materials which affect to the cracking reaction of long chain hydrocarbons into short chain hydrocarbons so that a part of liquid products will be converted to gaseous products.

The presence of the catalyst can enhance the cracking reaction of the pyrolysis gas. This further reaction increased the gas yield for all natural zeolite catalysts. Long chain hydrocarbons have been cracked into lighter hydrocarbon gases. Figure 5 indicates that $\mathrm{H}-\mathrm{NZ}$ catalyst produced slightly lower liquid yield than A-NZ catalyst due to the larger surface area of $\mathrm{H}-\mathrm{NZ}$ after the acid treatment which enhanced surface contact between the catalyst and the pyrolysis gas in the reformer. The similar result has also been found in Ni-NZ catalyst. The presence of nickel as a promoter could increase the activity of natural zeolites.

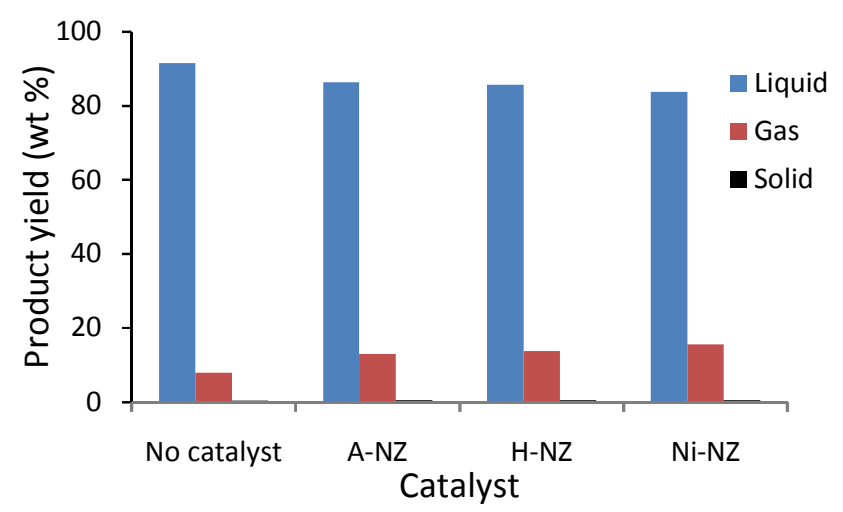

Figure 5. Product yields obtained from the pyrolysis and catalytic reforming of polypropylene in the absence and the presence of catalyst.

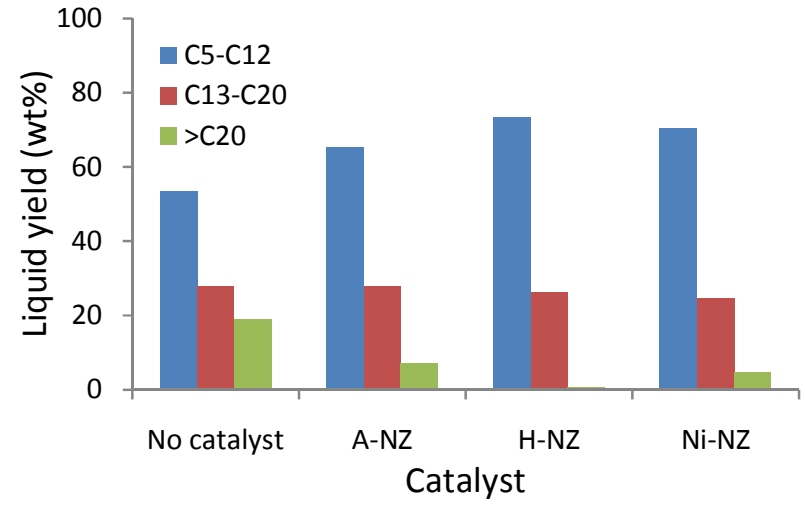

Figure 6. Liquid product composition obtained from the pyrolysis and catalytic reforming of polypropylene.

The composition of the liquid products have been changed by the presence of natural zeolite catalysts as shown in Figure 6. In general, the fraction of gasoline $\left(\mathrm{C}_{5^{-}}\right.$ $\mathrm{C}_{12}$ ) increased in the presence of the catalysts. The increase of the surface area and the presence of nickel significantly affected the selectivity of the products. The use of H-NZ catalyst increased the gasoline fraction compared to that of A-NZ catalyst. The higher surface area of $\mathrm{H}-\mathrm{NZ}$ catalyst promoted the cracking reaction of heavy oil. The presence of nickel in Ni-NZ catalyst also increased the gasoline fraction. However, it was lower than that of $\mathrm{H}-\mathrm{NZ}$ due to lower surface area of the catalyst. Impregnation of metal onto natural zeolite framework decreased its surface area. This phenomenon may be caused by the non homogeneous distribution of metal in the natural zeolite surface. Some of metal atoms may block the pore mouth of the zeolites[24]. The presence of the catalysts also significantly decreased the heavy oil fraction $\left(>\mathrm{C}_{20}\right)$. H-NZ catalyst produced the lowest heavy oil fraction. Figure 6 also showed no significant difference of the diesel fuel fractions $\left(\mathrm{C}_{13}-\mathrm{C}_{20}\right)$. A$\mathrm{NZ}$ catalyst produced slightly higher diesel fuel than that of the reforming without catalysts while $\mathrm{H}-\mathrm{NZ}$ and $\mathrm{Ni}-\mathrm{NZ}$ produced lower diesel fuel yields.

Figure 7 shows the gas yields obtained from the sequential pyrolysis and catalytic reforming of PP with various natural zeolite catalysts. It was found that propene was dominated in all conditions. The unidentified gaseous products might have been gaseous hydrocarbons containing more than three carbon atoms that could not be measured by our apparatus. The presence of natural zeolite catalysts increased the yield of propene, ethane and propane. The increase of some gases have been obtained from the conversion of oil to lighter hydrocarbons after the reaction with the catalysts. Ni-NZ catalyst has higher composition for all gases by the effect of nickel presence in the catalyst. The similar results have been obtained by Ji et al. [12] which produced very high composition of propene gas. In commercial scale application, the high quality gaseous product can be used as a fuel either for driving gas engines or for dual-fuel diesel engine. It can also be used as a heating source for the pyrolyzer. 


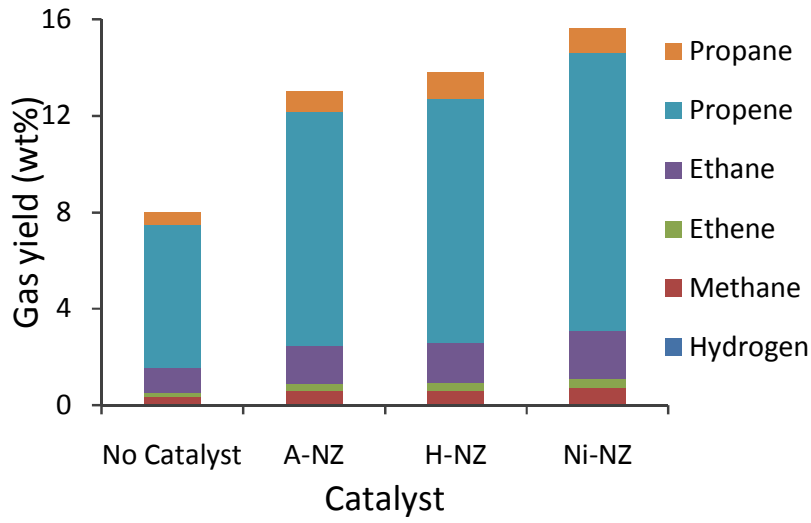

Figure 7. Gaseous product composition obtained from the pyrolysis and catalytic reforming of polypropylene.

\subsection{Pyrolysis and catalytic reforming of polystyrene}

Figure 8 shows the product yields obtained from the sequential pyrolysis and catalytic reforming of polystyrene (PS). PS was degraded at $500^{\circ} \mathrm{C}$ in the pyrolyzer and then reformed at $450^{\circ} \mathrm{C}$ in the catalytic reformer. The experiments were done in the same procedure and conditions with the experiments of PP. Pyrolysis of PS in the absence of the catalyst produced a liquid yield of $98 \%$. The similar results have also been found by Williams and Bagri [15] which obtained $96.6 \%$ oil. In the presence of the natural zeolite catalysts, the oil yields were reduced to about $85-95 \%$ depending on the catalysts used. A similar trend with PP has been observed for PS. The treatments of natural zeolite catalysts have been found to decrease the oil yield and increase the gas yield as can be seen for $\mathrm{H}-\mathrm{NZ}$ and $\mathrm{Ni}-\mathrm{NZ}$ catalysts compared with A-NZ catalyst. The lowest liquid product has been observed by $\mathrm{Ni}-\mathrm{NZ}$ catalyst. As discussed previously, the larger surface area of $\mathrm{H}-\mathrm{NZ}$ and the presence of nickel in Ni-NZ catalyst are the key factors for these findings. These conditions enhanced the catalytic performance of natural zeolites. The lower liquid products have been obtained by Williams and Bagri [15] which utilize commercial Y zeolite as a catalyst. This catalyst could produce oil between $69-75 \%$.

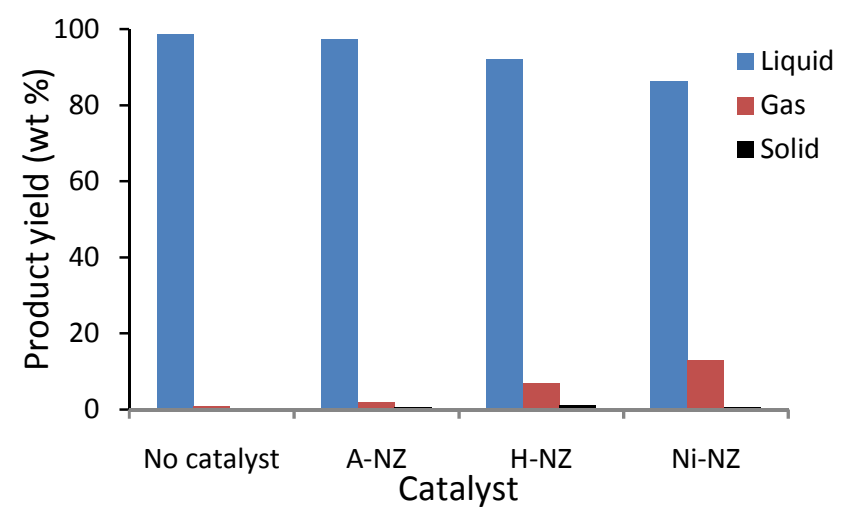

Figure 8. Product yields obtained from the pyrolysis and catalytic reforming of polystyrene in the absence and the presence of catalyst.

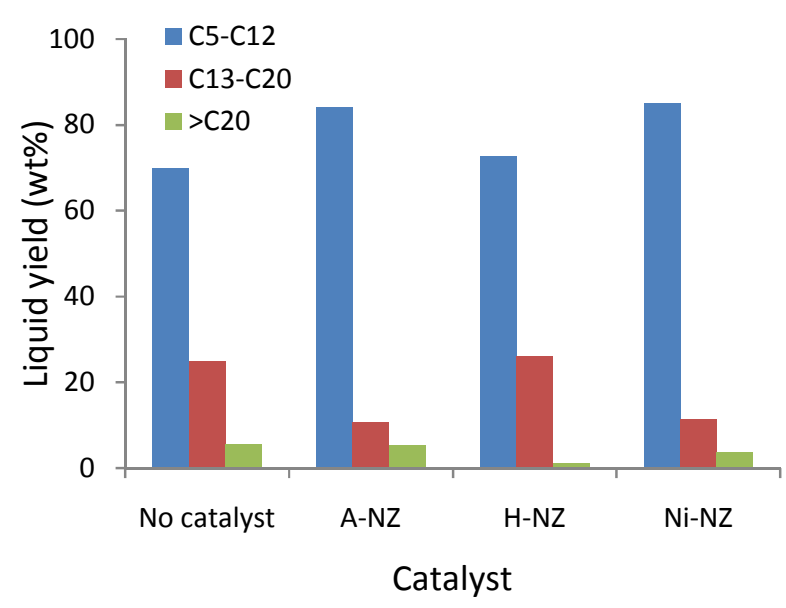

Figure 9. Liquid product composition obtained from the pyrolysis and catalytic reforming of polystyrene

The composition of liquid fuels in the sequential pyrolysis and catalytic reforming of PS is shown in Figure 9. The presence of the catalysts increased the yield of light oil $\left(\mathrm{C}_{5}-\mathrm{C}_{12}\right)$ while the heavier oil $\left(\mathrm{C}_{13}-\mathrm{C}_{20}\right)$ was decreased. However, H-NZ catalyst produced less light oil than others. This is due to the increase of $\mathrm{Si} / \mathrm{Al}$ ratio after the acid treatment which decreased the acidity of the catalyst. The liquid products were mainly composed of benzene, methylbenzene, ethylbenzene and styrene, which are valuable chemical feedstock and fuel used in our daily life and modern industry. In addition, there are some aromatic hydrocarbons existed in the PS oil, which were mainly consisted of some potentially harmful polycyclic aromatic hydrocarbons [25]. Therefore, if the oil derived from PS would be used as combustion fuel oil, these harmful polycyclic aromatic hydrocarbons should be removed in advance. Consequently, it is preferable to recycle the PS oil as chemical crude materials rather than as fuel oil [26].

The gas yields produced from the sequential pyrolysis and catalytic reforming processes of PS is shown in Figure 10. Propane and propene were the main components of the gas product in the presence of Ni-NZ catalyst. The presence of nickel increased the selectivity of the products. Reforming over H-NZ catalyst produced almost the similar proportion for all gases except for hydrogen. Propene was dominated in the reforming over A-NZ catalyst. The presence of the catalysts have significantly increased the gas yield compared with those of PP as shown in Figue 7. Williams and Bagri [15] reported slightly different results when utilizing ZSM-5 and Y zeolite catalysts. The main gases produced from the catalytic pyrolysis of PS were alkane and alkene gases from $\mathrm{C}_{1}$ to $\mathrm{C}_{4}$. Ethene and propene and lower concentrations of methane, ethane and propane were the main gases produced with the zeolite ZSM-5 catalyst, whereas equal concentrations of ethane, propene, methane, ethane and propane were produced with the $Y$ zeolite catalyst. 


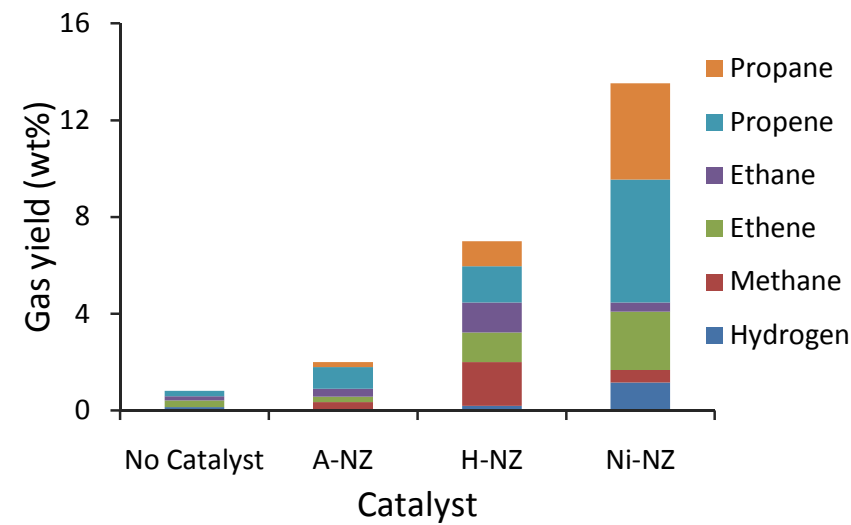

Figure 10. Gaseous product composition obtained from the pyrolysis and catalytic reforming of polystyrene.

\section{Conclusions}

The mordenite-type natural zeolites, either calcinations treatment (A-NZ) or $\mathrm{HCl}$ treatment $(\mathrm{H}-\mathrm{NZ})$ or nickel impregnation ( $\mathrm{Ni}-\mathrm{NZ}$ ) could be used as efficient catalysts for the conversion of PP and PS into liquid and gaseous fuels by the sequential pyrolysis and catalytic reforming processes. Natural zeolites after $\mathrm{HCl}$ treatment (H-NZ) showed an increase of the surface area and the Si/Al ratio compared with that of A-NZ catalyst. The presence of nickel in Ni-NZ increased the activity of the catalyst which enhanced the cracking reaction of pyrolysis gas. As a result, liquid product was reduced while gaseous product was increased.

For polypropylene, the fraction of gasoline $\left(\mathrm{C}_{5}-\mathrm{C}_{12}\right)$ increased in the presence of the catalysts. The use of $\mathrm{H}-\mathrm{NZ}$ catalyst increased the gasoline fraction compared with that of A-NZ catalyst. The presence of nickel in Ni-NZ catalyst also increased the gasoline fraction. However, it was lower than H-NZ catalyst due to a lower surface area of the catalyst. Natural zeolite catalysts could also be used to decrease the heavy oil fraction $\left(>C_{20}\right)$. It was found that the gaseous products was dominated by propene in all conditions. The presence of natural zeolite catalysts increased the yield of propene, ethane and propane.

Pyrolysis of polystyrene in the absence of the catalyst produced a liquid yield of $98 \%$. In the presence of the natural zeolite catalysts, the oil yields were reduced to about $85-95 \%$ depending on the catalysts used. The treatments of natural zeolite catalysts have been found to decrease the oil yield and increase the gas yield as can be seen for $\mathrm{H}-\mathrm{NZ}$ and $\mathrm{Ni}-\mathrm{NZ}$ catalysts compared with A-NZ catalyst. The presence of catalysts increased the yield of light oil $\left(\mathrm{C}_{5}-\mathrm{C}_{12}\right)$ while the heavier oil $\left(\mathrm{C}_{13}-\mathrm{C}_{20}\right)$ was decreased. Propane and propene were the main components of gases in the presence of $\mathrm{Ni}-\mathrm{NZ}$ catalyst. Reforming over H-NZ catalyst produced almost the similar proportion for all gases except for hydrogen. Propene was dominated in the reforming over A-NZ catalyst. The high quality gaseous product can be used as a fuel either for driving gas engines or for dual-fuel diesel engine.

\section{Acknowledgments}

The authors would like to thank JICA AUN/SEED-Net for providing scholarship during the study. The authors would also like to thank PT. Khatulistiwa Hijau Prima, Indonesia for providing natural zeolite samples.

\section{References}

[1] Lee, S.Y., Yoon, J.H., Kim, J.R., Park, D.W., 2001. Catalytic degradation of polystyrene over natural clinoptilolite zeolite. Polymer Degradation and Stability, 74, 297-305.

[2] UNEP, 2009. Converting waste plastics into resource: compendium of technologies. United Nations Environment Programme, Osaka.

[3] Aguado, J., Serrano, D.P., San Miguel, G., Castro, M.C., Madrid, S., 2007. Feedstock recycling of polyethylene in a two-step thermocatalytic reaction system. Journal of Analytical and Applied Pyrolysis, 79, 415-423.

[4] Buekens, A.G., Huang, H., 1998. Catalytic plastics cracking for recovery of gasoline-range hydrocarbons from municipal plastic wastes. Resources, Conservation and Recycling, 23, 163-181.

[5] Miskolczi, N., Nagy, R., 2012. Hydrocarbons obtained by waste plastic pyrolysis: Comparative analysis of decomposition described by different kinetic models. Fuel Processing Technology, 104, 96-104

[6] Hussain, Z., Khan, K.M., Perveen, S., Hussain, K., Voelter, W., 2012. The conversion of waste polystyrene into useful hydrocarbons by microwave-metal interaction pyrolysis. Fuel Processing Technology, $94,145-150$.

[7] Lin, H.-T., Huang, M.-S., Luo, J.-W., Lin, L.-H., Lee, C.-M., Ou, K.-L., 2010. Hydrocarbon fuels produced by catalytic pyrolysis of hospital plastic wastes in a fluidizing cracking process. Fuel Processing Technology, 91, 1355-1363.

[8] Seo, Y.-H., Lee, K.-H., Shin, D.-H., 2003. Investigation of catalytic degradation of high-density polyethylene by hydrocarbon group type analysis. Journal of Analytical and Applied Pyrolysis, 70, 383398.

[9] Mikulec, J., Vrbova, M., 2008. Catalytic and thermal cracking of selected polyolefins. Clean Technologies and Environmental Policy, 10, 121-130.

[10] Wang, J.L., Wang, L.L., 2011. Catalytic Pyrolysis of Municipal Plastic Waste to Fuel with Nickel-loaded Silica-alumina Catalysts. Energy Sources, Part A: Recovery, Utilization, and Environmental Effects, 33, 1940-1948.

[11] Miskolczi, N., Angyal, A., Bartha, L., Valkai, I., 2009. Fuels by pyrolysis of waste plastics from agricultural and packaging sectors in a pilot scale reactor. Fuel Processing Technology, 90, 1032-1040.

[12] X. Ji, J.L.Q.J.Q.W., 2001. Study on the Conversion of Polypropylene Waste to Oil in a Fluidized Bed Reactor. Energy Sources, 23, 157-163.

[13] Onwudili, J.A., Insura, N., Williams, P.T., 2009. Composition of products from the pyrolysis of polyethylene and polystyrene in a closed batch reactor: Effects of temperature and residence time. Journal of Analytical and Applied Pyrolysis, 86, 293-303.

[14] Bagri, R., Williams, P.T., 2002. Catalytic pyrolysis of polyethylene. Journal of Analytical and Applied Pyrolysis, 63, 29-41.

[15] Williams, P.T., Bagri, R., 2004. Hydrocarbon gases and oils from the recycling of polystyrene waste by catalytic pyrolysis. International Journal of Energy Research, 28, 31-44.

[16] San Miguel, G., Serrano, D.P., Aguado, J., 2009. Valorization of Waste Agricultural Polyethylene Film by Sequential Pyrolysis and Catalytic Reforming. Industrial \& Engineering Chemistry Research, 48, 86978703. 
[17] Cakicioglu-Ozkan, F., Ulku, S., 2005. The effect of $\mathrm{HCl}$ treatment on water vapor adsorption characteristics of clinoptilolite rich natural zeolite. Microporous and Mesoporous Materials, 77, 47-53.

[18] Jeong, S., Kim, J.-H., Seo, G., 2001. Liquid-phase degradation of HDPE over alkali-treated natural zeolite catalysts. Korean Journal of Chemical Engineering, 18, 848-853.

[19] Park, D.W., Hwang, E.Y., Kim, J.R., Choi, J.K., Kim, Y.A., Woo, H.C., 1999. Catalytic degradation of polyethylene over solid acid catalysts. Polymer Degradation and Stability, 65, 193-198.

[20] Fernandes, V.J., Jr., Araujo, A.S., Medeiros, R.A., Matos, J.R., Mercuri, L.P., Silva, A.O., Melo, D.M.A., 1999. Kinetic Parameters of Polyethylene Degradation by the Natural Zeolite Chabazite. Journal of Thermal Analysis and Calorimetry, 56, 1279-1282.

[21] Hwang, E.-Y., Kim, J.-R., Choi, J.-K., Woo, H.-C., Park, D.-W., 2002. Performance of acid treated natural zeolites in catalytic degradation of polypropylene. Journal of Analytical and Applied Pyrolysis, 62, 351-364.
[22] Trisunaryanti, W., Shiba, R., Miura, M., Nomura, M., Nishiyama, N., Matsukata, M., 1996. Characterization and modification of Indonesian natural zeolites and their properties for hydrocracking of a paraffin. Sekiyu Gakkaishi 39, 20-25.

[23] Sarker, M., Rashid, M.M., Molla, M., Waste polypropylene plastic conversion into liquid hydrocarbon fuel for producing electricity and energies. Environmental Technology, 33, 2709-2721.

[24] Trisunaryanti, W., Triyono, Rizki, C.N., Saptoadi, H., Alimuddin, Z., Syamsiro, M., Yoshikawa, K., 2013. Characteristics of Metal Supported-Zeolite Catalysts for Hydrocracking of Polyethylene Terephthalat. IOSR Journal of Applied Chemistry, 3, 29-34.

[25] Lee, S.-Y., Yoon, J.-H., Park, D.-W., 2002. Catalytic degradation of mixture of polyethylene and polystyrene. J. Ind. Eng. Chem, 8, 143149.

[26] Joo, H.S., Guin, J.A., 1997. Hydrocracking of a Plastics Pyrolysis Gas Oil to Naphtha. Energy \& Fuels, 11, 586-592. 